\title{
Cell cycle and apoptosis regulatory gene expression in the bone marrow of patients with de novo myelodysplastic syndromes (MDS)
}

\author{
Christina Economopoulou • Vassiliki Pappa - Sotiris Papageorgiou • Frieda Kontsioti • \\ Panagiota Economopoulou • Efstratia Charitidou • Kostas Girkas • \\ Violetta Kapsimali • Chrissoula Papasteriadi • Panagiotis Tsirigotis • \\ Efstathios Papageorgiou • John Dervenoulas • Theofanis Economopoulos
}

Received: 23 March 2009 / Accepted: 15 September 2009 /Published online: 8 October 2009

(C) Springer-Verlag 2009

\begin{abstract}
Deregulation of cell cycle and apoptosis pathways are known contributors to the pathogenesis of myelodysplastic syndromes (MDS). However, the underlying mechanisms are not fully clarified. The aim of our study was to examine mRNA expression levels of cell cycle and apoptosis regulatory genes, as well as the percentage of apoptotic and S phase cells and to correlate the findings with clinical characteristics and prognosis. Sixty patients with MDS, classified according to FAB (17 RA, five RARS, 19 RAEB, nine RAEBT, ten CMML) and WHO (ten RA, three RARS, seven RCMD, two RCMD-RS, 11 RAEBI, eight RAEBII, ten CMML, and nine AML) were included in the study. We found increased expression of anti-apoptotic bclxL and mcll genes and decreased expression of $\mathrm{p} 21$ gene in MDS patients. Moreover,
\end{abstract}

Electronic supplementary material The online version of this article (doi:10.1007/s00277-009-0835-2) contains supplementary material, which is available to authorized users.

C. Economopoulou $(\bowtie) \cdot V$. Pappa $\cdot S$. Papageorgiou $\cdot$

F. Kontsioti · P. Economopoulou $\cdot$ K. Girkas $\cdot$ P. Tsirigotis •

E. Papageorgiou $\cdot$ J. Dervenoulas $\cdot$ T. Economopoulos

Attikon University Hospital,

2nd Propedeutic Clinic of Internal Medicine,

1 Rimini Str., Haidari,

Athens, Greece

e-mail: chris_oiko@yahoo.com

E. Charitidou

School of Applied Mathematical and Physical Sciences,

National Technical University of Athens,

Athens, Greece

V. Kapsimali $\cdot$ C. Papasteriadi

Department of Immunology-Histocompatibility,

Evangelismos Hospital,

Athens, Greece we found increased expression of anti-apoptotic mcll gene in patients with higher than Intermediate-1 IPSS group. Multivariate analysis confirmed that combined expression of apoptotic caspases 8, 3, 6, 5, 2, 7, and Granzyme B was decreased in MDS patients. Regarding cell cycle regulatory genes expression, we demonstrated increased expression of cyclin D1 in patients with CMML Increased combined expression of cyclins B, C, D1, and D2 was found in patients with cytogenetic abnormalities. The two pathways seem to be interconnected as shown by the positive correlation between CDKs 1, 2, 4, p21 and the level of apoptosis and positive correlation between apoptotic caspase 3 expression and the percentage of S phase cells. In conclusion, our study showed altered expression of genes involved in apoptosis and cell cycle in MDS and increased expression of cyclin D1 in patients with CMML.

Keywords Myelodysplastic syndromes · Cell cycle . Apoptosis · Cyclin D1 · CMML

\section{Introduction}

MDS constitute a heterogeneous group of clonal hematopoietic disorders that exhibit ineffective hematopoiesis with an increased risk of transformation to acute myeloid leukemia (AML) [1-3]. Almost one third of the bone marrow cells of MDS patients are engaged in DNA synthesis [4-8]. The increased rate of cell birth is canceled by an equally increased rate of cell death resulting in peripheral cytopenias. Moreover, many bone marrow cells of patients suffering from MDS are simultaneously engaged in DNA synthesis and apoptosis, a phenomenon called "signal antonymy", so 
far only seen in MDS biopsies. Review data support that in the early phase of the disease, increased apoptosis is associated with ineffective progenitor and maturing hematopoietic cell survival and associated cytopenias. The progression of MDS to AML occurs concomitantly with decreased apoptosis and an increased degree of neoplastic cell survival, leading to subsequent expansion of the abnormal precursor cells [1,9-11]. Therefore, the study of cell cycle and apoptotic regulatory machinery in MDS turns to be of great importance and interest.

The heart of the regulatory apparatus during cell cycle progression is a family of enzymes, called cyclin-dependent kinases (CDKs). CDKs are divided into two groups, based on their roles in cell cycle progression and transcriptional regulation. The first group is comprised by core components of the cell cycle machinery and includes CDK1, CDK2, CDK3, CDK4, and CDK6. The second group is comprised by regulators of transcription and includes CDKs 7,8 , and $9[12$, 13]. CDKs need to be associated with specific cyclins, in order to be activated. Active complexes of cyclins and CDKs exert their biological effects by phosphorylating various cytoplasmic proteins. CDK/cyclin complexes are turned off by cyclin-dependent kinase inhibitors (CKIs). Two families of CKIs have been identified; INK family includes four members: INK4A or p16, INK4B or p15, INK4C or p18, and INK4D or p19, whereas CIP/KIP family includes CIP1 or $\mathrm{p} 21, \mathrm{KIP} 1$ or $\mathrm{p} 27$, and KIP2 or $\mathrm{p} 57$.

bcl2 family is a large family of proteins, including proapoptotic and anti-apoptotic members, which are involved in the activation of caspases, a family of cytosolic proteases, the effector molecules of apoptosis [2, 11]. We have previously published a study of caspases and bcl2 family mRNA expression and of apoptosis in the bone marrow of 46 patients with MDS [14].

The aim of the present study was to examine CDKs, cyclins, and CKIs mRNA expression, the degree of apoptosis and the percentage of cells in the $\mathrm{S}$ phase of cell cycle in the bone marrow (BM) of adult patients with de novo MDS. We also used the data from our previous study concerning apoptosis regulation genes - caspases and bcl2 family genes - and we enriched this study with 14 more cases with MDS. Our objective was to identify different expression patterns of cell cycle and apoptosis regulatory genes at different stages of MDS and to correlate the findings with clinical characteristics and prognosis.

\section{Materials and methods}

Patients

A total of 60 MDS patients, 40 male patients and 20 female patients, classified according to FAB classification as follows: 17 RA, 5 RARS, 19 RAEB, 9 RAEBT, and 10 CMML and to WHO classification as follows: 10 RA, 3 RARS, 7 RCMD, 2 RCMD-RS, 11 RAEBI, 8 RAEBII, 10 CMML, and 9 AML, were included in our study. Twelve healthy individuals were used as normal controls (five female and seven male donors, median age 51 years, age range 37-71 years). Fresh samples of BM aspirates were obtained at diagnosis from the patients as well as the control group. Informed consent was obtained from each MDS patient as well as each healthy donor. The median age of patients was 72 years (range 55-89 years). Their clinical and hematological features are summarized in Table 1 and the precise karyotypic abnormalities of patients with abnormal karyotype are shown on Table 2.

\section{Total RNA extraction}

Total RNA was isolated from the bone marrow samples using the Tripure Isolation Reagent (GIBCO), according to

Table 1 Clinical features of MDS patients

\begin{tabular}{|c|c|}
\hline \multicolumn{2}{|l|}{ Clinical parameter } \\
\hline Age (median value) & 71 years (range $55-89$ ) \\
\hline $\mathrm{Hb}$ (median value) & $9.75 \mathrm{~g} / \mathrm{dl}$ (range $6.5-14)$ \\
\hline $\begin{array}{l}\text { WBC neutrophils } \\
\text { (median value) }\end{array}$ & $\begin{array}{l}\left.8,606 / \mathrm{mm}^{3} \text { (range } 1,500-23,000\right) \\
\left.2,340 / \mathrm{mm}^{3} \text { (range } 150-10,500\right)\end{array}$ \\
\hline PLT (median value) & $135,375 / \mathrm{mm}^{3}$ (range $\left.13,000-777,000\right)$ \\
\hline Blasts (median value) & $5 \%$ (range $0-30 \%$ ) \\
\hline \multicolumn{2}{|l|}{ Patients } \\
\hline Sex & $\begin{array}{l}\text { Male, } 40 \\
\text { Female, } 20\end{array}$ \\
\hline FAB classification & $\begin{array}{l}\text { RA, } 17 \\
\text { RARS, } 5 \\
\text { RAEB, } 19 \\
\text { RAEBT, } 9 \\
\text { CMML, } 10\end{array}$ \\
\hline WHO classification & $\begin{array}{l}\text { RA10 } \\
\text { RCMD, } 7 \\
\text { RARS, } 3 \\
\text { RCMD-RS, } 2 \\
\text { RAEBI, } 11 \\
\text { RAEBII, } 8 \\
\text { AML, } 9 \\
\text { CMML1, } 10\end{array}$ \\
\hline Karyotype & $\begin{array}{l}\text { Normal, } 26 \\
\text { Abnormal, } 17 \\
\text { Non defined, } 17\end{array}$ \\
\hline IPSS & $\begin{array}{l}\leq 1,33 \\
>1,11 \\
\text { Non defined, } 6\end{array}$ \\
\hline
\end{tabular}


Table 2 Cases with abnormal karyotype

Patients with abnormal karyotype

3 cases with RA

4 cases with RAEBT

1 case with CMML
1 case with RARS

8 cases with RAEB

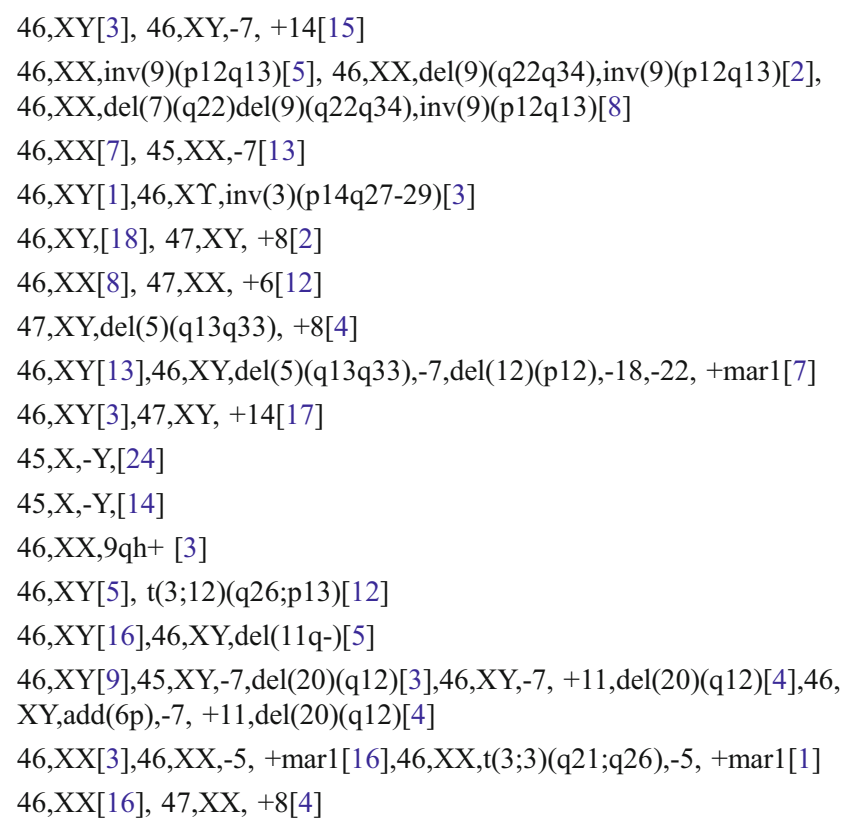

a modified guanidine-thiocyanate method. Then, chloroform extraction, isopropanol precipitation, and quantification by spectrophotometry were performed.

\section{RNase protection assay}

The ribonuclease protection assay (RPA) is a highly sensitive and specific method for the detection and quantification of multiple mRNA species.

Ten micrograms of RNA were analyzed with h-CC1 and h-CYC1 Riboquant kits. These panels explored the mRNA encoding for CDKs and CKIs, i.e. CDKs 1, 2, 3, 4, p27, p21, and p16 (h-CC1) and cyclins, i.e., cyclins A, B, C, D1, D2, and A1 (h-CYC1). h-Apolb and h-Apo2b Riboquant kits, encoding for caspases $1,2,3,5,6,7,8,9$ and Granzyme B (h-Apolb) and bcl2 family, i.e., bclxL, bclxS, bfl1, bik, bak, bax, bcl2, mcl1 (h-Apo2b) were also included in our study. Each of the four kits also detected and quantified mRNA encoding two ubiquitous genes: GAPDH and L32. Briefly, riboprobes were synthesized using a ${ }^{32} \mathrm{P}-\mathrm{UTP}$ and then purified by phenol-chloroform extraction and ethanol precipitation. Riboprobes target mRNA hybridization was performed overnight at $56^{\circ} \mathrm{C}$. Samples were then digested by ribonucleases $\mathrm{A}$ and $\mathrm{T} 1$ for $45 \mathrm{~min}$ at $30^{\circ} \mathrm{C}$. Then, after $15 \mathrm{~min}$ of proteinase $\mathrm{K}$ digestion at $37^{\circ} \mathrm{C}$, phenol-chloroform extraction and ethanol precipitation were performed. The samples were resuspended in a formamide-based loading dye and loaded on to a $5 \%$ polyacrylamide $/ 7 \mathrm{M}$ urea denaturing gel.
Following migration (55 W for $90 \mathrm{~min}$ ), the gel was dried, exposed, and scanned. Intensity of gene bands, L32 and GAPDH mRNA were measured by phosphorimaging (Image Master Software-Pharmacia).

The quantity of each mRNA species was determined based on the housekeeping genes L32 and GAPDH. Data were expressed as the relative ratio of each gene to these genes' mRNA level. We observed that the respective ratios for each gene did not differ; consequently, the integrity as well as the security of the RPA method is considered to be guaranteed.

\section{Annexin V staining}

Cells to be stained were washed twice in phosphatebuffered saline and then resuspended in a $1 \times$ binding buffer at a concentration of $10^{6}$ cells $/ \mathrm{ml}$. Cells were then incubated with $10 \mu \mathrm{l}$ of fluorescein-conjugated annexin V and $10 \mu \mathrm{l}$ of PI. Annexin V binds to those cells that express phosphatidylserine on the outer layer of the cell membrane whereas PI stains the cellular DNA of those cells with a compromised cell membrane. This allows for live cells (unstained with either fluorochrome) to be discriminated from apoptotic cells (stained only with annexin V) and necrotic cells (stained with both annexin and PI). The apoptotic index was calculated as the percentage of annexin-V-positive- and PI-negative cells divided by the total number of cells in the gated region [15]. 
Analysis of cell cycle using flow cytometry

For the analysis of cell cycle, DNA Prep reagent kit (PN 6607055, Beckman Coulter) was used. One hundred microliters of single cell suspension are added to $100 \mu \mathrm{L}$ of LPR, to obtain a final cell concentration of $3-5 \times 10^{6}$ cells/mL. After vortex, $2 \mathrm{~mL}$ of DNA Prep Stain are added, to be followed by vortex and filter with a $25-\mu \mathrm{m}$ filter tip into a sample cup. Analysis follows. Flow cytometry offers a rapid method for measuring the DNA content of cells and provides a convenient research tool to monitor cell cycle status and regulation. An exponentially growing population of cells will have a DNA content distribution containing an initial peak of Go/G1 cells, a valley of $\mathrm{S}$ phase cells and a second peak containing G2/M cells.

\section{Statistical analysis}

Statistical analysis was performed using STATA 8.0 and SPSS version 11.0 (SPSS Inc., Chicago, IL, USA) [16-18].

Spearman correlation coefficient test was used to evaluate the strength of association between the continuous variables, i.e., gene-expression values and the degree of apoptosis, as well as CDKs', CKIs', and cyclins' expression values among themselves retrospectively. Mann-Whitney $U$ test for independent samples was used for comparison of gene-expression values between IPSS, FAB, WHO, hemoglobulin - $\mathrm{Hb}$, white blood cell counts-WBC, platelets-PLT and percent blast categories, as well as for comparison of gene-expression values between MDS patients and healthy donors.

For multivariate gene analysis, principal component analysis, and discriminant analysis were used. These two methods allow the study of many variables simultaneously, inform about how the original variables are correlated, and show how the samples are grouped. $[19,20]$

We divided the patients' population into two subgroups based on IPSS score. The first, low-risk group consisted of patients with IPSS score $\leq 1$, whereas the members of the second, high-risk group had IPSS score $>1$. In addition, patients were separated according to FAB and WHO classification as low-risk MDS (RA and RARS, according to FAB and RA, RARS, RCMD, RCMD-RS according to WHO) and high-risk MDS (RAEB and RAEB-t, according to FAB and RAEBI and RAEBII, according to WHO). Finally, patients with CMML were analyzed separately.

For each hematological parameter (Hb, WBC, PLT) two groups were designed, those of normal and of abnormal values. Regarding bone marrow blasts, patients were separated into four distinct groups: $<5 \%, 5-10 \%, 10-20 \%$ and $>20 \%$. As far as karyotype is concerned, we used the distinction of two groups (normal and abnormal karyotype), but we also tested gene-expression differences between patients with single and complex abnormalities, as well as in patients with normal karyotype, in comparison to those with del-5q and monosomy 7 .

\section{Results}

Gene-expression study

All genes were expressed at the mRNA level in patients and normal controls. Gene-expression levels were diverse. The expression of p21 was found lower in patients compared to healthy donors $\left(p<0.05^{*}\right)$, whereas that of bclxL and mcll was statistically higher in patients compared to normal controls ( $p<0.05^{*}$ and $p<0.01^{*}$, respectively). The expression of the other genes did not differ between patients and controls. Examples of the final autoradiographic plates of the RNAase protection assay are shown on Fig. 1.

Patients with CMML exhibited higher cyclin D1 levels, compared to the other two FAB subgroups $\left(p<0.02^{*}\right.$, RA-RARS Median value 0.3925-range

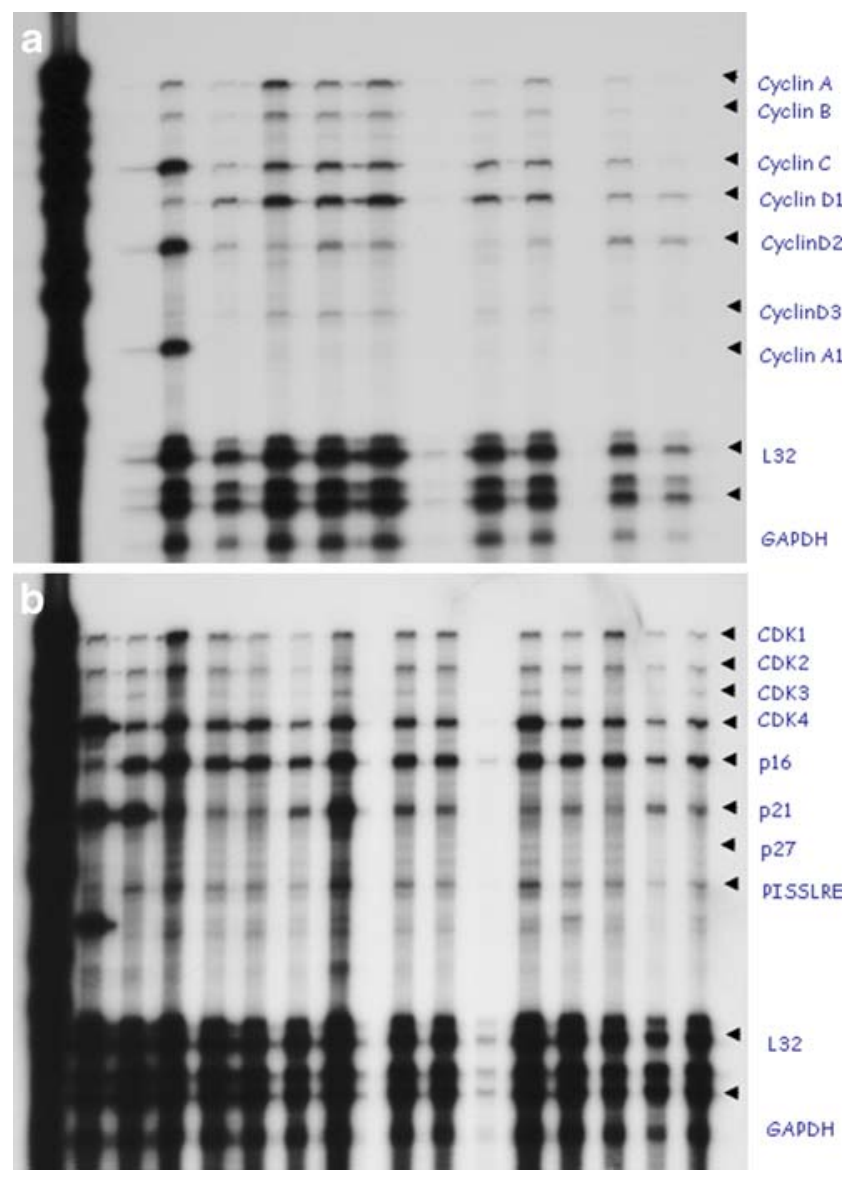

Fig. 1 Example of autoradiographic plates of RNAase protection assay (RPA). The samples were hybridized with h-CYC1 (1A) and hCC1 (1B). Marked bands indicate the various mRNA species detected in MDS samples. Each mRNA band of interest is expressed as a percent of L32 and GAPDH 
0-63.328, RAEB-RAEBT Median value 0.193-range 0-24.25, CMML Median value 1.3275-range 0.31615.063). This correlation is described on Fig. 2a. Geneexpression levels of the rest of the genes were not significantly different between low- and high-risk MDS patients, according to FAB and WHO subgroups.

Regarding IPSS score, patients with IPSS $>1$ showed higher expression of mcll gene, compared to patients with IPSS $\leq 1(p<0.02 *)$. This correlation is described on Fig. $2 b$. Expression levels of CDKs, CKIs, cyclins, and the rest of apoptosis regulatory genes were not significantly different between different IPSS risk categories. The expression levels of all genes showed no statistically significant correlation with hematological parameters, percentage of marrow blasts $(<5 \%, 5-10 \%, 10-20 \%,>20 \%)$ and karyotype (normalabnormal, single vs complex abnormalities, normal karyotype vs del-5q vs monosomy 7).

We also tried to find out if specific patterns of gene expression were specifically associated with diverse patients' subgroups. Principal component analysis revealed that combined expression of caspases 8, 3, 6, 5, 2, 7 and Granzyme B is approximately 3,724 times lower in patients compared to
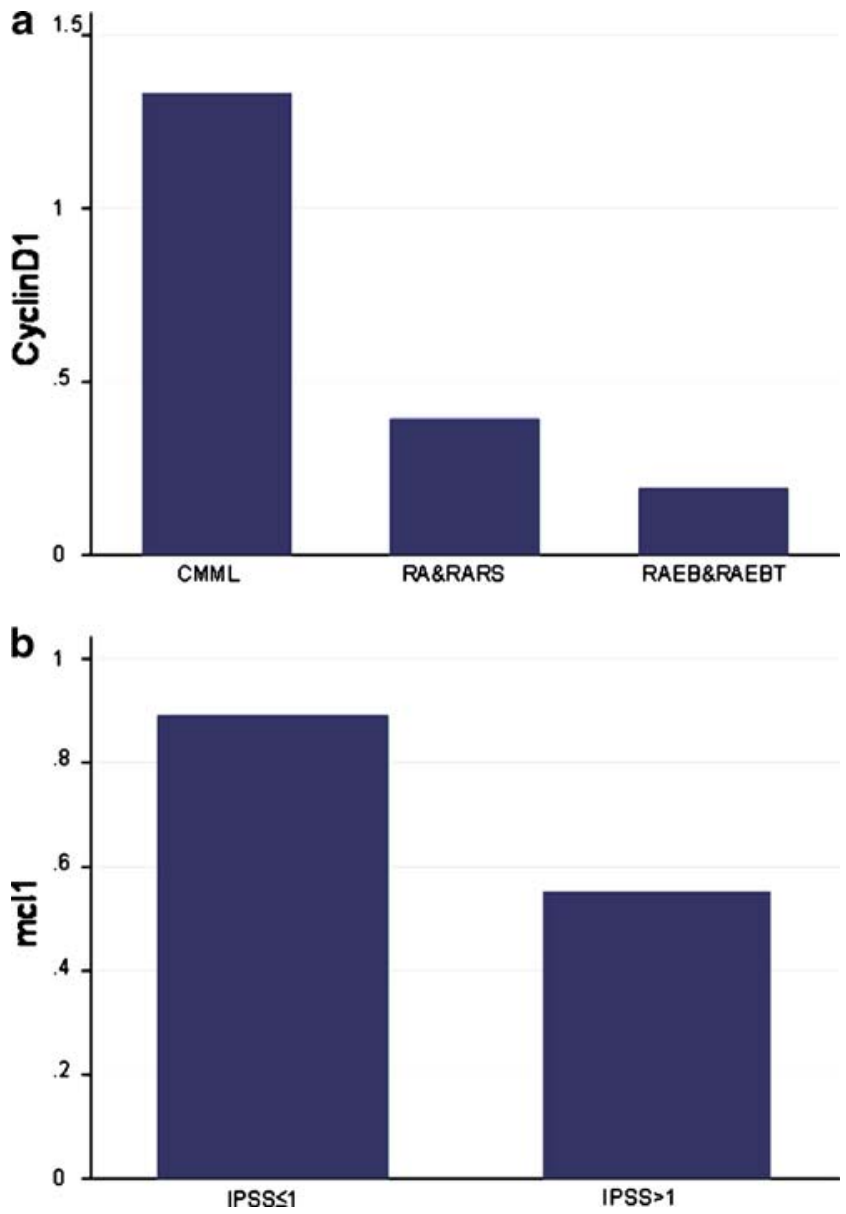

Fig. 2 a Median values of Cyclin D1 by FAB categories. b Median values of mcll by IPSS categories healthy donors $(p<0.01 *, 95 \%$ CI $-6,133,-1,314)$. In addition, this method revealed that combined expression of cyclins B, C, D1, and D2 turns to be roughly 2,394 times higher in patients with abnormal karyotype $\left(p<0.01^{*}, 95 \%\right.$ CI 0,646, 4,141).

For the same objective, discriminant analysis was used; the results of the two methods are in agreement. Patients had lower scores of the discriminant function compared to healthy individuals (Wilks' Lambda $=0.155$, Chi-square $=$ $82,961, p<0.01 *)$. The 12 genes with the higher contribution to the discriminant function between patients and controls were the following: caspase 7, caspase 2L, CDK4, CDK1, cyclin A, which had positive contribution and caspase $2 \mathrm{~S}$, caspase $5, \mathrm{CDK} 2$, caspase 8 , cyclin $\mathrm{C}$, cyclin A1 and p16, which had negative contribution.

Regarding clinical parameters of the patients, discriminant function was statistically significant only for karyotype. Patients with abnormal karyotype had lower scores of the discriminant function than patients with normal karyotype (Wilks' Lambda=0.095, Chi-square $=54.129, p<$ $0.01 *)$. Genes with the higher contribution were $\mathrm{p} 27$, cyclin D1, p21, and caspase 2, which had positive contribution to the function and $\mathrm{CDK} 4$, cyclin $\mathrm{B}$, caspase 6 , and CDK2 with negative contribution.

The results of discriminant analysis are described on Fig. 3 and the statistical method is analyzed in Supplement 1.

S phase

The median value of S phase cells for all MDS patients using flow cytometry was $10.6 \%$ (range $0.19-27.4$ ) and did not statistically differ between MDS patients and healthy donors (median value $8.7 \%$, range $0.02-23.8$ ). The percentage of cells in the $\mathrm{S}$ phase did not correlate with the values of the hematological parameters of the patients $(\mathrm{Hb}, \mathrm{WBC}, \mathrm{PLT}$, and percent blasts) and FAB, WHO, and IPSS subgroups. We found a statistically significant positive correlation between $\mathrm{S}$ phase and the levels of expression of caspase $3\left(p<0.05^{*}\right)$. An example of cell cycle graph is being shown on Fig. 4.

\section{Apoptosis}

The percentage of annexin-positive cells, indicating the rate of apoptosis of MDS patients was 2.79\% (range 0-34.9) and did not statistically differentiate between MDS patients and healthy donors (median value $2.01 \%$, range $0-28.2$ ). Also, no statistically significant differentiation was found between FAB, WHO and IPSS subgroups of patients. Finally, the rate of apoptosis did not correlate with the values of the hematological parameters of the patients.

A positive correlation was found between CDKs' 1,2 and $4\left(p<0.02^{*}, p<0.02 *\right.$, and $p<0.01^{*}$, respectively) and p21 $(p<0.02 *)$ expression and the percentage of annexin- 

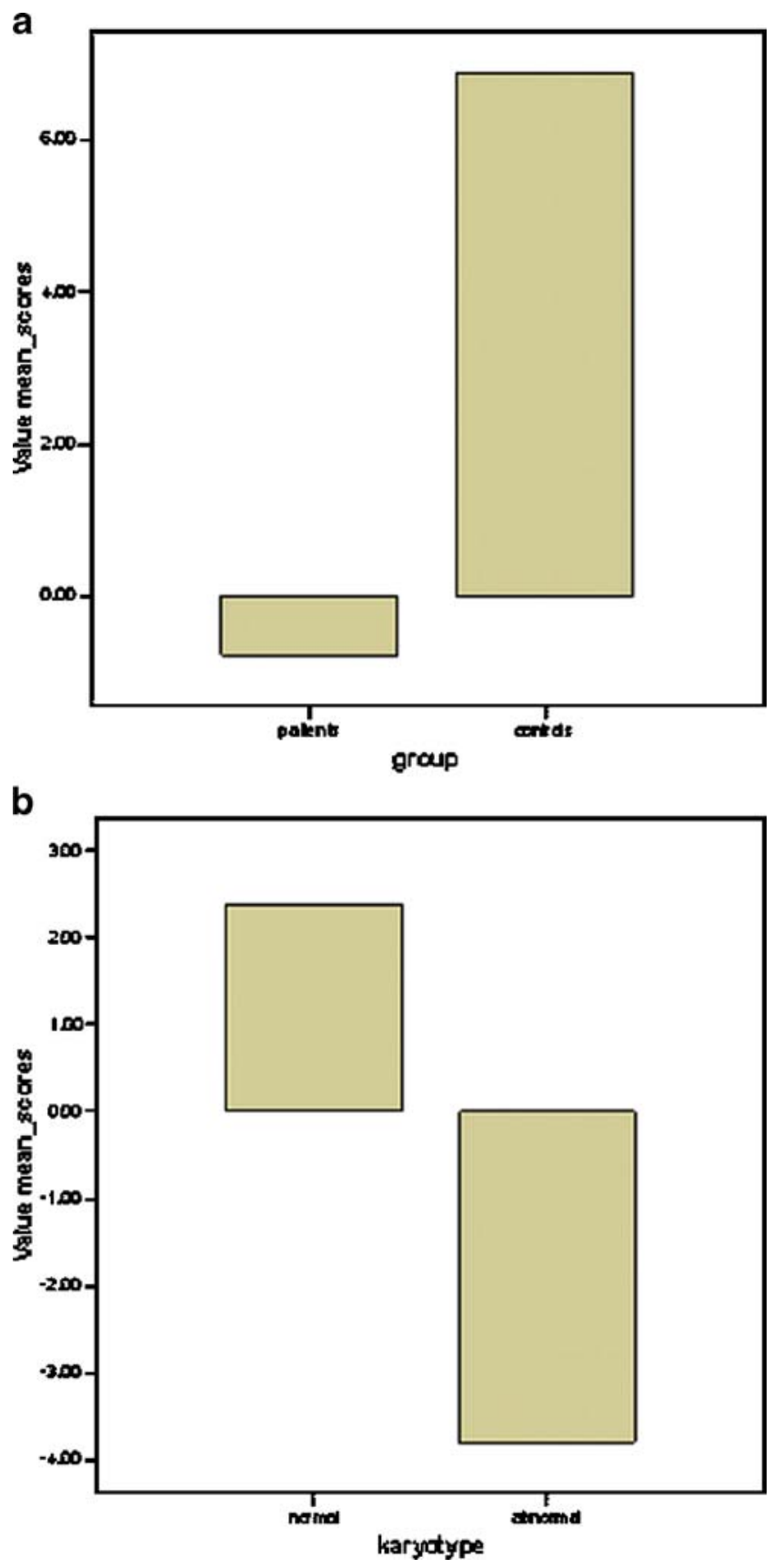

Fig. 3 Discriminant analysis. a Patients versus normal controls. The median value of discriminant function is clearly lower in patients. $\mathbf{b}$ Normal versus abnormal karyotype. The median value of discriminant function is clearly lower in patients with abnormal karyotype

positive cells. On the contrary, the expression of cyclins, CDK3, p27, p16, and PISSLRE did not correlate with the percentage of annexin-positive cells.

\section{Discussion}

Cell division and apoptosis are key aspects of MDS pathophysiology. The combination of increased cell prolif- eration and reduced cell death lies very close to disease progression. Although the cell division cycle and apoptosis might appear to be quite different from a physiological perspective, recent evidence suggests that they are intertwined, and that an enzyme in one system might also have an important role in the other system. [21, 22]

The degree of apoptosis in our study is relatively lower than previously reported with annexin $\mathrm{V}$ staining [15, 23, 24]. Similar were the findings of our previous study in a smaller group of patients [14]. This could be partly explained taking into consideration that we used isolated BM mononuclear cells for the detection of apoptosis, in contrast with most studies with annexin $\mathrm{V}$ method, whereby $\mathrm{CD} 34+$ progenitor cells were selected [25]. Evaluation of BM mononuclear cells rather than stem cells alone may lead to underestimation of the degree of apoptosis. Indeed, a study using annexin V method co-staining with CD34, showed increased annexin $\mathrm{V}$ binding in CD34+ cells in MDS [26]. Other investigators have also reported that apoptosis was mainly seen in immature $\mathrm{CD} 34+$ progenitors, after separation of marrow cells into CD34+ and CD34cell fractions $[6,11,27]$. The fact that apoptosis in the FAB low-risk group was higher than that in the FAB high-risk group, although not significantly different, is in accordance with a number of previous studies [1, 6, 10, 11, 25, 28]. The increased apoptosis observed in "early" MDS is possibly a physiological mechanism whereby the hematopoietic system is able to eliminate potentially harmful

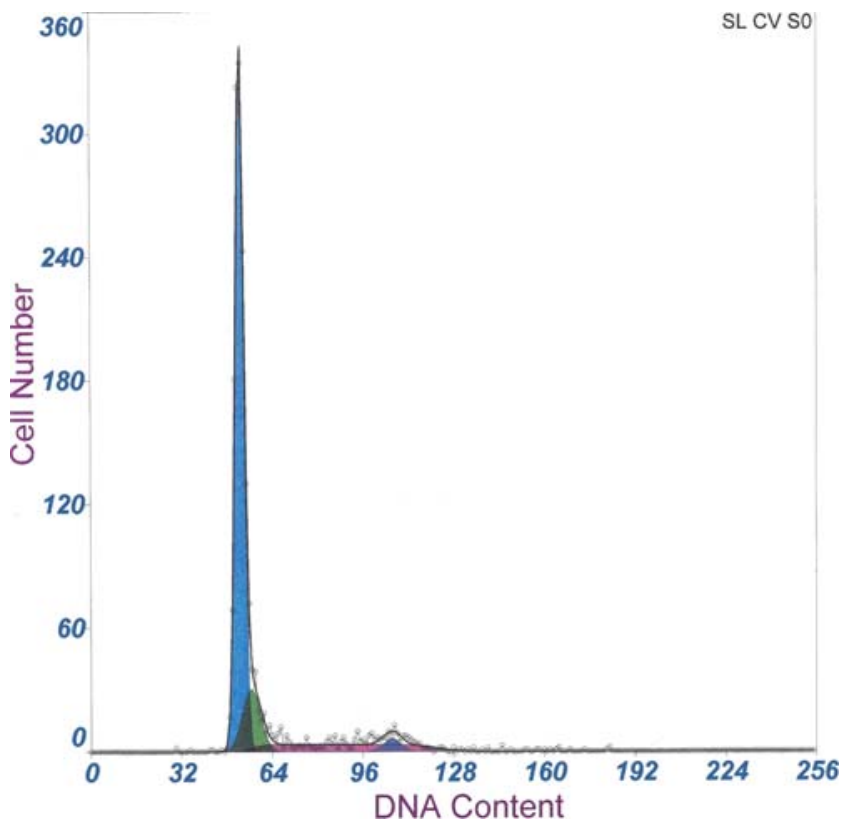

Fig. 4 Example of the cell cycle graph by flow cytometry. The initial peak corresponds to cells at the Go/G1 phase, the valley following represents $\mathrm{S}$ phase cells, whereas the second, lower peak refers to G2/ $\mathrm{M}$ cells 
clones. It is a kind of homeostatic process in order to control cell numbers [6].

Studies of the cell cycle in MDS in the last few years have focused on epigenetic alterations of key molecules of the cell cycle, particularly CKIs p16 and p15 [29]. Publications focusing on molecules, at the mRNA or protein level, which might influence cell cycle kinetics in MDS, are limited. The median value of $\mathrm{S}$ phase cells in our study is in the limits of bibliography data and is found higher from that of normal individuals, yet not reaching statistical significance. Evaluation of BM mononuclear cells rather than stem cells alone may also play an important role and lead to an underestimation of the percentage of the cells at the $\mathrm{S}$ phase of the cell cycle. Indeed, it has been demonstrated that an enhanced cyclic activity in MDS patients can be demonstrated in vivo [30]. The percentage of cells at the $\mathrm{S}$ phase of the cell cycle did not correlate with clinical parameters $(\mathrm{Hb}, \mathrm{WBC}, \mathrm{PLT}$, and percent blasts), or with gene expression, with the exception of caspase 3. The importance of this finding remains unclear, as the involvement of caspases in cell cycle has not really been investigated. However, a recent study suggested that caspase 3 is activated in cells entering late G1 or early $\mathrm{S}$ phase, and caspase 8 is activated in middle or late G1 phase in asynchronously growing leukemia cells [31].

The positive correlation of apoptosis to CDKs 1, 2, and 4 in our study comes in accordance with data from bibliography that suggest that CDKs' activity is required in a subset of apoptosis programs [32, 33]. However, the specific point of action of CDKs is unclear [34] and there also exist a number of studies that suggest that CDKs' inhibition promotes apoptosis [35-39]. In favor of a direct participation are several studies linking apoptosis with elevated CDK levels. For example, a number of studies link CDK1 activity with Granzyme B-induced apoptosis, staurosporin-induced apoptosis in FT210 cells, HIV-1 Tatinduced apoptosis, T-cell death by anti-CD3 antibodies and apoptosis of human promyelocytic leukemia cells, HL60 [34, 39]. In addition, microtubule inhibitors such as paclitaxel (Taxol) have been found to increase the activity of CDK1 in several breast cancer cell lines [34, 38]. The involvement of other kinases in the apoptotic pathways is also a fact. CDK2 is induced after treatment with HIV-1 Tat [34]. In apoptotic thymocytes, CDK2 activation is required for cell death and only occurs subsequent to bax expression or bcl 2 repression [40]. In addition, upregulation of CDK4 may be a primary and critical factor in induction of apoptosis in human lung carcinomas in vivo [41]. A provocative conclusion concerning CDK4 comes from another study: up-regulation of CDK4 kinase activity is characterized as the primary and critical mediator of apoptosis regardless the cell types [32, 42-44].

Our results link also p21 expression to the degree of apoptosis. Among CKIs, p21 is one of the most highly studied for its involvement in apoptosis [45, 46]. The majority of bibliographic data though support the idea that p21 may act as an apoptosis inhibitor, in contradiction to our results [44]. There are yet a number of reports that suggest a pro-apoptotic function of p21 under certain conditions in specific systems and are in agreement with our findings [47-56]. Further investigation of the role of p21 in apoptosis is required.

Interestingly, according to our results, p21 expression turns out to be lower in patients compared to healthy donors. The progression of MDS to AML occurs concomitantly with decreased apoptosis and an increased degree of neoplastic cell survival, leading to subsequent expansion of the abnormal precursor cells. A potential explanation of the lower p21 expression, which we found in patients with MDS compared to normal controls, comes from its known function. p21 is an inhibitor of cell cycle, inactivating $\mathrm{CDK} /$ cyclin complexes and its lower expression could favor disease progression. Additionally, our study links p21 expression with the degree of apoptosis, as already mentioned. Apoptosis is a physiological mechanism whereby the hematopoietic system is able to eliminate potentially harmful clones. It is a kind of homeostatic process in order to control cell numbers [6]. Lower p21 expression in patients could also be explained through the suppression of the apoptotic pathway that characterizes patients compared to healthy donors.

To our knowledge, we report for the first time that patients with CMML show higher cyclin D1 mRNA expression. According to WHO classification, CMML has been placed in a new category of diseases, named myelodysplastic/myeloproliferative disorders [57-60]. Although two categories of CMML are recognized by the WHO, based on the percentage of combined blasts and promonocytes in the blood, the ambiguity in the clinical and morphologic findings is unquestionable and the diagnostic term encompasses a wide spectrum of diseases. It is possible that the overexpression of cyclin D1 has to do exactly with the myeloproliferative character of CMML, which distinguishes it from MDS. Increased expression of cyclin D1 is a feature of many different primary human tumors with current diagnostic and prognostic implications. Cyclin D1 could be a very interesting target for therapeutic intervention and anti-cyclin D1 agents are in development. Our findings propose that cyclin D1 may provide a basis for treatment of patients with CMML. We consider this finding really important and having a potential practical use, as far as it is confirmed at protein level.

In order to identify specific groups of genes, whose combined expression pattern could characterize specific groups of patients or could distinguish between patients and healthy individuals, we used multivariate analysis. To our knowledge, we report for the first time that such a correlation is being established. The results of principal component 
analysis indicate that combined expression of six caspases, 8 , 3, 6, 5, 2, 7, and Granzyme B was lower in MDS patients than normal individuals. This finding is in agreement with the findings of discriminant analysis and both methods have high levels of sensitivity in our study. Discriminant function turned to have lower scores in patients compared to normal controls, and what is really interesting is that the genes with the higher contribution to the discriminant function were caspases 7,2,5, and 8. In other words, caspases turned to have lower expression values in MDS patients. This finding further stresses the importance of the apoptotic process in the pathogenesis of MDS and provides a gene-expression model for the group of patients that could even serve for screening purposes in the future.

Multivariate analysis with both methods also led to interesting conclusions regarding karyotype. Principal component analysis indicated that combined expression of cyclins B, C, D1, and D2 is higher in patients with abnormal karyotype. Discriminant analysis also led to the same conclusion. This finding could explain a proliferative advantage of these cases leading to a higher probability of detecting of karyotypic abnormalities. Cyclins constitute master regulators of the cell cycle. Their combined aberrant expression in MDS patients could lead to aberrant cell proliferation, which, together with the lower rates of protective apoptotic cell death, could result in inaccurate elimination of unwanted and defective cells and to increased genomic instability $[4,34]$.

In addition, we found increased expression of mcll gene in patients of the IPSS high-risk group (IPSS $>1$ ). The activity of cell death pathways depends on the relative expression of pro and anti-apoptotic bcl2 genes. As soon as the balance favors anti-apoptotic genes, mcll is overexpressed, the disease progresses, IPSS score raises, and this is probably concomitant with an increased immature cellular survival and neoplastic cell expansion. We consider the overexpression of mcll gene in patients with IPSS $>1$ an important finding, as it can serve in the future as a prognostic marker for patients of this stage of disease, provided that it is confirmed at the protein level. Furthermore, we found higher expression of the anti-apoptotic bclxL and mcll genes in MDS patients compared to normal donors. This finding also supports the previously mentioned theory.

In summary, our study revealed different expression of specific genes between patients and healthy donors (p21, bclxL, and mcl1), correlation of specific genes with the degree of apoptosis (CDKs 1,2,4, p21), with specific clinical features of patients (cyclin D1 with CMML category) and with the IPSS score (mcl1). Moreover, our multivariate analysis revealed lower combined expression of caspases $8,3,6,5,2,7$, and Granzyme $\mathrm{B}$ in MDS compared to controls and higher combined cyclin B, C, D1, and D2 expression in patients with abnormal karyotype compatible with a higher proliferation rate and a higher probability of revealing karyotypic abnormalities. Taking into consideration the multifactorial pathogenetic features of MDS, as well as the therapeutic dilemmas that often occur, we consider the developing understanding of cell cycle and apoptosis function essential, with the view to proceed to molecularly targeted treatment and improved clinical outcome.

Acknowledgment This work was supported in part by a grant-in-aid from the Hellenic Cooperative Oncology Group (HeCoG).

\section{References}

1. Greenberg PL (1998) Apoptosis and its role in the myelodysplastic syndromes: implications for disease natural history and treatment. Leuk Res 22:1123

2. Greenberg PL (1996) Biologic and clinical implications of marrow culture studies in the myelodysplastic syndromes. Semin Hematol 33:163

3. Economopoulos T, Stathakis N, Foudoulakis A, Papadoulis N, Dervenoulas J, Papageorgiou E, Anastassiou C, Hadjioannou J, Raptis S (1987) Myelodysplastic syndromes: analysis of 131 cases according to the FAB classification. Eur J Haematol 38:338

4. Raza A, Gezer S, Mundle S, Gao XZ, Alvi S, Borok R, Rifkin S, Iftikhar A, Shetty V, Parcharidou A et al (1995) Apoptosis in bone marrow biopsy samples involving stromal and hematopoietic cells in 50 patients with myelodysplastic syndromes. Blood 86:268

5. Raza A, Mundle S, Iftikhar A, Gregory S, Marcus B, Khan Z, Alvi S, Shetty V, Dameron S, Wright V et al (1995) Simultaneous assessment of cell kinetics and programmed cell death in bone marrow biopsies of myelodysplastics reveals extensive apoptosis as the probable basis for ineffective hematopoiesis. Am J Hematol 48:143

6. Parker JE, Fishlock KL, Mijovic A, Czepulkowski B, Pagliuca A, Mufti GJ (1998) 'Low-risk' myelodysplastic syndrome is associated with excessive apoptosis and an increased ratio of pro- versus anti-apoptotic bcl-2-related proteins. Br J Haematol 103:1075

7. Yoshida Y (1993) Hypothesis: apoptosis may be the mechanism responsible for the premature intramedullary cell death in the myelodysplastic syndrome. Leukemia 7:144

8. Raza A, Alvi S, Borok RZ, Span L, Parcharidou A, Alston D, Rifkin S, Robin E, Shah R, Gregory SA (1997) Excessive proliferation matched by excessive apoptosis in myelodysplastic syndromes: the cause-effect relationship. Leuk Lymphoma 27:111

9. Shimazaki K, Ohshima K, Suzumiya J, Kawasaki C, Kikuchi M (2002) Apoptosis and prognostic factors in myelodysplastic syndromes. Leuk Lymphoma 43:257

10. Yoshida Y, Mufti GJ (1999) Apoptosis and its significance in MDS: controversies revisited. Leuk Res 23:777

11. Rajapaksa R, Ginzton N, Rott LS, Greenberg PL (1996) Altered oncoprotein expression and apoptosis in myelodysplastic syndrome marrow cells. Blood 88:4275

12. Shapiro GI (2006) Cyclin-dependent kinase pathways as targets for cancer treatment. J Clin Oncol 24:1770

13. Sridhar J, Akula N, Pattabiraman N (2006) Selectivity and potency of cyclin-dependent kinase inhibitors. AAPS J 8:E204

14. Economopoulou C, Pappa V, Kontsioti F, Papageorgiou S, Kapsimali V, Papasteriadi C, Economopoulou P, Papageorgiou E, Dervenoulas J, Economopoulos T (2008) Analysis of apoptosis 
regulatory genes expression in the bone marrow (BM) of adult de novo myelodysplastic syndromes (MDS). Leuk Res 32:61

15. Merchant SH, Gonchoroff NJ, Hutchison RE (2001) Apoptotic index by Annexin V flow cytometry: adjunct to morphologic and cytogenetic diagnosis of myelodysplastic syndromes. Cytometry 46:28

16. Campbell MJ (2002) Statistics at Square One

17. Campbell MJ (2001) Statistics at square Two: understanding modern statistical applications in medicine

18. Petrie CS (2000) Medical statistics at a glance

19. Chan YH (2005) Discriminant Analysis. Biostatistics 303, Singapore Med Journal:54

20. Johnson RA, Wichern DW (2002) Applied multivariate statistical analysis

21. Borgne A, Golsteyn RM (2003) The role of cyclin-dependent kinases in apoptosis. Prog Cell Cycle Res 5:453

22. Arai S, Miyake K, Voit R, Nemoto S, Wakeland EK, Grummt I, Miyazaki T (2007) Death-effector domain-containing protein DEDD is an inhibitor of mitotic Cdk1/cyclin B1. Proc Natl Acad Sci U S A 104:2289

23. Vermes I, Haanen C, Steffens-Nakken H, Reutelingsperger C (1995) A novel assay for apoptosis. Flow cytometric detection of phosphatidylserine expression on early apoptotic cells using fluorescein labelled Annexin V. J Immunol Methods 184:39

24. Koopman G, Reutelingsperger CP, Kuijten GA, Keehnen RM, Pals ST, van Oers MH (1994) Annexin V for flow cytometric detection of phosphatidylserine expression on B cells undergoing apoptosis. Blood 84:1415

25. Parker JE, Mufti GJ, Rasool F, Mijovic A, Devereux S, Pagliuca A (2000) The role of apoptosis, proliferation, and the Bcl-2related proteins in the myelodysplastic syndromes and acute myeloid leukemia secondary to MDS. Blood 96:3932

26. Lin CW, Manshouri T, Jilani I, Neuberg D, Patel K, Kantarjian H, Andreeff M, Estrov Z, Beran M, Keating M, Estey E, Albitar M (2002) Proliferation and apoptosis in acute and chronic leukemias and myelodysplastic syndrome. Leuk Res 26:551

27. Tsoplou P, Kouraklis-Symeonidis A, Thanopoulou E, Zikos P, Orphanos V, Zoumbos NC (1999) Apoptosis in patients with myelodysplastic syndromes: differential involvement of marrow cells in 'good' versus 'poor' prognosis patients and correlation with apoptosis-related genes. Leukemia 13:1554

28. Bouscary D, Chen YL, Guesnu M, Picard F, Viguier F, Lacombe C, Dreyfus F, Fontenay-Roupie M (2000) Activity of the caspase$3 / \mathrm{CPP} 32$ enzyme is increased in "early stage" myelodysplastic syndromes with excessive apoptosis, but caspase inhibition does not enhance colony formation in vitro. Exp Hematol 28:784

29. Li Y, Dida F, Iwao A, Deguchi T, Azuma E, Komada Y (2007) Cell cycle dependency of caspase activation in Fas-induced apoptosis in leukemia cells. Cancer Sci 98:1174

30. Agool A, Schot BW, Jager PL, Vellenga E (2006) 18F-FLT PET in hematologic disorders: a novel technique to analyze the bone marrow compartment. J Nucl Med 47:1592

31. Bennett JM (2000) World Health Organization classification of the acute leukemias and myelodysplastic syndrome. Int J Hematol 72:131

32. Burhans WC, Weinberger M, Marchetti MA, Ramachandran L, D'Urso G, Huberman JA (2003) Apoptosis-like yeast cell death in response to DNA damage and replication defects. Mutat Res $532: 227$

33. Harvey KJ, Blomquist JF, Ucker DS (1998) Commitment and effector phases of the physiological cell death pathway elucidated with respect to Bcl-2 caspase, and cyclin-dependent kinase activities. Mol Cell Biol 18:2912

34. Pucci B, Kasten M, Giordano A (2000) Cell cycle and apoptosis. Neoplasia 2:291

35. Shi L, Chen G, He D, Bosc DG, Litchfield DW, Greenberg AH (1996) Granzyme B induces apoptosis and cyclin A-associated cyclin-dependent kinase activity in all stages of the cell cycle. $\mathrm{J}$ Immunol 157:2381

36. Greenberg AH (1996) Activation of apoptosis pathways by granzyme B. Cell Death Differ 3:269

37. Greenberg AH (1996) Granzyme B-induced apoptosis. Adv Exp Med Biol 406:219

38. Kasten MM, Giordano A (1998) pRb and the cdks in apoptosis and the cell cycle. Cell Death Differ 5:132

39. Castedo M, Perfettini JL, Roumier T, Kroemer G (2002) Cyclindependent kinase-1: linking apoptosis to cell cycle and mitotic catastrophe. Cell Death Differ 9:1287

40. Dobashi Y, Goto A, Fukayama M, Abe A, Ooi A (2004) Overexpression of cdk4/cyclin D1, a possible mediator of apoptosis and an indicator of prognosis in human primary lung carcinoma. Int J Cancer 110:532

41. Katayama K, Dobashi Y, Kitagawa M, Kawai M, Kadoya Y, Kameya T (2003) Cdk4/cyclin D1 kinase, a universal and critical regulator of apoptosis. Anticancer Res 23:235

42. Maddika S, Ande SR, Panigrahi S, Paranjothy T, Weglarczyk K, Zuse A, Eshraghi M, Manda KD, Wiechec E, Los M (2007) Cell survival, cell death and cell cycle pathways are interconnected: implications for cancer therapy. Drug Resist Updat 10:13

43. Weinberg WC, Denning MF (2002) P21Wafl control of epithelial cell cycle and cell fate. Crit Rev Oral Biol Med 13:453

44. Gartel AL, Tyner AL (2002) The role of the cyclin-dependent kinase inhibitor p21 in apoptosis. Mol Cancer Ther 1:639

45. Janicke RU, Sohn D, Essmann F, Schulze-Osthoff K (2007) The multiple battles fought by anti-apoptotic p21. Cell Cycle 6:407

46. Schwartz GK (2002) CDK inhibitors: cell cycle arrest versus apoptosis. Cell Cycle 1:122

47. Shadduck RK, Latsko JM, Rossetti JM, Haq B, Abdulhaq H (2007) Recent advances in myelodysplastic syndromes. Exp Hematol 35:137

48. Hopfer O, Komor M, Koehler IS, Schulze M, Hoelzer D, Thiel E, Hofmann WK (2007) DNA methylation profiling of myelodysplastic syndrome hematopoietic progenitor cells during in vitro lineage-specific differentiation. Exp Hematol 35:712

49. Solomon PR, Munirajan AK, Tsuchida N, Muthukumarasamy K, Rathinavel A, Selvam GS, Shanmugam G (2008) Promoter hypermethylation analysis in myelodysplastic syndromes: diagnostic \& prognostic implication. Indian J Med Res 127:52

50. Rosu-Myles M, Wolff L (2008) p15Ink4b: dual function in myelopoiesis and inactivation in myeloid disease. Blood Cells Mol Dis 40:406

51. Muller CI, Ruter B, Koeffler HP, Lubbert M (2006) DNA hypermethylation of myeloid cells, a novel therapeutic target in MDS and AML. Curr Pharm Biotechnol 7:315

52. Aggerholm A, Holm MS, Guldberg P, Olesen LH, Hokland $P$ (2006) Promoter hypermethylation of p15INK4B, HIC1, CDH1, and $\mathrm{ER}$ is frequent in myelodysplastic syndrome and predicts poor prognosis in early-stage patients. Eur J Haematol 76:23

53. Boultwood J, Wainscoat JS (2007) Gene silencing by DNA methylation in haematological malignancies. Br J Haematol 138:3

54. Leone G, Voso MT, Teofili L, Lubbert M (2003) Inhibitors of DNA methylation in the treatment of hematological malignancies and MDS. Clin Immunol 109:89

55. Vidal DO, Lopes LF, Valera ET (2007) Drug resistance and methylation in myelodysplastic syndrome. Curr Pharm Biotechnol 8:77

56. Papageorgiou SG, Pappa V, Papageorgiou E, Tsirigotis P, Kontsioti F, Panani A, Dervenoulas J, Economopoulos T (2005) Absence of p16 and p27 gene rearrangements and mutations in de novo myelodysplastic syndromes. Eur J Haematol 75:193

57. Donnellan R, Chetty R (1998) Cyclin D1 and human neoplasia. Mol Pathol 51:1 
58. Alao JP (2007) The regulation of cyclin D1 degradation: roles in cancer development and the potential for therapeutic invention. Mol Cancer 6:24

59. Kenny FS, Hui R, Musgrove EA, Gee JM, Blamey RW, Nicholson RI, Sutherland RL, Robertson JF (1999) Overexpression of cyclin D1 messenger RNA predicts for poor prognosis in estrogen receptor-positive breast cancer. Clin Cancer Res 5:2069

60. Hui R, Finney GL, Carroll JS, Lee CS, Musgrove EA, Sutherland RL (2002) Constitutive overexpression of cyclin D1 but not cyclin E confers acute resistance to antiestrogens in T-47D breast cancer cells. Cancer Res 62:6916 